\title{
Yerel Yönetimlerde Bilişim Teknolojileri Kullanımı, Yeterliği ve Halkla İlişkiler: Kocaeli Örneği
}

DOI: 10.26466/opus.734149

\author{
Burcu Üzüm* - Leyla Şenol ** \\ * Dr., Kocaeli Üniversitesi, Kocaeli MYO, Başiskele / Kocaeli / Türkiye \\ E-Posta: burcugokay@gmail.com \\ ORCID: $\quad \underline{0000-0001-8675-8952}$ \\ **Dr., Kocaeli Üniversitesi, Ali Rıza Veziroğlu MYO, Kartepe / Kocaeli/ Türkiye \\ E-Posta: senolleyla4@gmail.com \\ ORCID: $\underline{0000-0002-5780-9690}$
}

\section{Öz}

$\mathrm{Bu}$ araştırma ile yerel yönetim çalışanlarının bilişim teknolojileri kullanımı yeterliliği, bilişim teknolojileri kullanımının avantajları ve halkla ilişkiler uygulamaları hakkındaki algılarının ölçülmesi amaçlanmıştır. Çalışmada tarama modeli kullanılmıştır. Araştırma evrenini İzmit, Başiskele, Gölcük ilçe belediye çalışanları oluşturmaktadır. Örneklem seçiminde kolayda örneklem metodu tercih edilmiştir. Örneklem; İmit, Başiskele ve Gölcük belediyelerindeki 181 çalışandan oluşmaktadır. Temel Teknoloji Yeterlikler ve alt boyutlarının halkla ilişkiler ve alt boyutlarıyla arasında pozitif bir ilişki görülmüştür. Biliş̧im teknolojileri avantajı ve alt boyutları halkla ilişkiler ve alt boyutlar ile pozitif bir ilişki içerisindedir. Cinsiyet, gelir, medeni durum, pozisyon ve kıdemin temel teknoloji yeterlikler, bilişim teknolojileri avantajı ve halkla ilişkiler üzerinde farklılık yaratmadığı belirlenmiştir. Demografik değiş̧kenlerden yaş ve eğitim düzeyinin temel teknoloji yeterlikler, bilişim teknolojileri avantajı ve halkla ilişkiler üzerinde farklılık yarattığı görülmüştür. Çalışanların temel teknoloji yeterlikler düzeyleri arttıkça bilişim teknolojileri avantajı, halkla ilişkiler algı düzeylerinin arttı̆̆ını belirtmek mümkündür.. Vatandaşlara uygun bir şekilde hizmet vermek için çalışanların bilişim teknolojilerini etkin bir şekilde kullanması gerekmektedir. Yerel yönetimlerin çalışanlarının eğitim ihtiyaçlarını göz önünde bulundurması önerilmektedir.

Anahtar Kelimeler: Yerel yönetimler, Bilişim teknolojileri kullanımı, Yeterliği ve Halkla ilişkiler. 


\title{
Information Technologies Usage, Competence and Public Relations in Local Administrations: The Case of Kocaeli
}

\begin{abstract}
This research was aimed to measure the competence of local government employees regarding information technology usage, advantages of information technology usage and the perceptions about public relations practices. Screening model was used in the study. The research population consists of the employees of Izmit, Basiskele and Gölcük district municipality. In sampling selection, easy sampling method was preferred. The sample consists of 181 employees in Izmit, Basiskele and Golcuk municipalities. It was observed that the basic technology competencies and their sub-dimensions showed a positive relationship with public relations and their sub-dimensions. It is seen that the advantage and sub-dimensions of information technologies are in a positive relationship between public relations and subdimensions. It has been indicated that gender, income, marital status, position and seniority do not make any difference on basic technology competencies, information technology advantage and public relations. It was observed that age and education level among demographic variables made a difference on basic technology competencies, information technology advantage and public relations. It is possible to claim that as the basic technology competence levels of the employees increase, their level of information technology advantage and public relations perception also increase. Employees must use information technologies effectively to serve citizens appropriately. It is recommended that local governments take the training needs of their employees into account.
\end{abstract}

Keywords: Local governments, Information technology usage, Competence and Public relations 


\section{Giriş}

Küreselleşme; teknolojinin gelişmesiyle sosyal ve kamusal hayatın yeniden şekillenmesine neden olurken; devlet, kültür ve kurumsal yapılar üzerinde bir köprü kurmak ve enformasyon ağıyla tüm bu yapıları harekete geçirmektedir (Castells, 2000). Küreselleşme, teknolojik gelişmeler toplumsal ihtiyaçlar ve beklentiler konusunda da değişim yaratmıştır. Kısaca yönetimlerde euygulamaların kullanılması küreselleşmenin bir sonucudur. Küreselleşme ile mekansal sınırlar ortadan kalkmış, ulaşım ve iletişim maliyetleri düşmüştür (Aktel, 2003). Bilişim teknolojilerinin gelişimiyle birlikte kağıt üzerinde gerçekleştirilen bürokratik işlemlerin ve bilginin dijital ortama aktarılmasını sağlayan değişim; organizasyonlarda ve devlet kurumlarında da kendini göstermiştir (Coşkun ve Uzun, 1999).

Kamu yönetimi açısından e-devlet, e-belediyecilik gibi isimlerle anılmaya başlayan bilişim teknolojilerinin kamuya hizmet alanında kullanılması hesap verilebilirlik, şeffaflık, bilgiye en hızlı şekilde ulaşılmasını sağlayan bir unsur olarak yönetimde yerini almaya başlamıştır. Bilgi teknolojileri ile iletişim teknolojilerinin kesişimi bilişim teknolojileri olarak adlandırılır (Karbuz, 2003). Bilişim teknolojilerinin kapsamında yer alan E-devlet uygulamaları tüm ülke vatandaşlarının; e-belediyecilik ise o il veya ilçe sınırlarında yaşayan vatandaşların kullanabildiği bir hizmettir. Bu çalışmada yerel yönetimler, yerel yönetimlerde bilişim teknolojileri ve yakından ilgili olduğu kavramlardan biri olarak halkla ilişkiler kavramları açıklanmaya çalışılmıs; sözü edilen kavramları, yerel yönetim çalışanlarının nasıl algıladıklarını tespit etmek amaçlanmıştır. Çalışanların demografik değişenlerinin bilişim teknolojileri kullanımı, yeterliği ve halkla ilişkiler üzerinde farklılık yaratıp yaratmadığı da incelenmiştir.

\section{Yerel Yönetimler, Bilişim Teknolojileri, Halkla İlişkiler}

E-devlet kavramı sosyo-ekonomik ihtiyaçlar sonucu ortaya çıkmıştır. E devlet uygulamaları, bürokratik süreçleri kısaltarak verimliliği artırırken vatandaş katılım-denetim ilişkisini kurmuştur. E kavramının kullanılmasıyla edevlet, e-belediye, e-banka, e-ticaret gibi kavramlar sosyal hayatta yerini almıştır (Yıldırım ve Öner, 2004). E-Devleti; “kamu hizmetlerinin, vatandaşlara, çalışanlara ve iş ortaklarına bilgi toplumu vasıtasıyla ulaşmalarını ve 
bundan yararlanmalarını sağlayan organizasyon" şeklinde tanımlamak mümkündür. E-devlet uygulamaları ülkedeki tüm vatandaşları kapsarken, e-belediyecilik uygulamaları o yörenin vatandaşlarına hizmet sunmaktadır.

Yerel yönetim; ortak ihtiyaçlara sahip yerel toplulukların ihtiyaçlarını karşlamak amacıyla belli bir hukuk düzeni içinde oluşturulmuş anayasal bir kurumdur (Nadaroğlu, 2000). Hukuksal dayanağı kamu tüzel kişiliği olan doğrudan yerel halka hizmet eden birimlerdir. Başka bir tanıma göre yerel yönetimler; "bulunduğu sınırlardaki halkın ihtiyaçlarını etkin bir biçimde karşılamak üzere, yerel topluluğa kamu hizmeti sağlayan ve yerel halkın kendi seçtiği organlarca yönetilen; yönetsel, siyasal ve toplumsal kurumlardır" (Ulusoy ve Akdemir, 2002).

Yerel yönetimler kendini seçen halka doğrudan hizmet vermektedir. Vatandaşlar, yerel yönetimlerde oy verip yönetimin başına gelecek olan kişiyi seçmektedirler. Bu açıdan e-belediyecilik seçilen ve seçen arasındaki ilişkiyi de düzenlemektedir. E-belediyecilik; "bilgi aktarımı dışında yerel yönetimlerle vatandaşlar arasındaki ilişkinin niteliğini veya iki taraf arasında yürütülen işlemlerin dönüşümünü sağlar" (Anttiroiko, 2001).

Doğrudan halka hizmet eden birimler olarak da belediyeler halkın denetiminde olan bir organizasyondur. Verilen hizmet açısından halkın memnun edilmesi tekrar seçilmek ve sürdürülebilir bir hizmet kalitesi, güven ortamı yaratmak yerel yönetimlerde önemlidir. Bilgi teknolojilerinin kullanıldığı sistemlerle yürütülen yönetim anlayışında vatandaş denetleyici rolünü de üstlenmektedir. Yerel yönetimlerin hizmet sunma etkinliği sahip oldukları bilgi teknolojilerinin gelişmesiyle mümkün olabilmektedir (Rahman, 2010).

Bilişim teknolojilerinin kamu hizmetlerinde kullanılması vatandaşlar açısından kolaylık getirmiştir. Vatandaşların belediyelere konumsal olarak aynı mesafede olmamaları, halkın yönetime etkin olarak katılımını sağlaması, 7/24 hizmet sunma imkanı tanıması, bilgi akışının hızlı olması gibi neden-sonuç ilişkisi etkisiyle yerel yönetimlerde bilgi teknolojileri kullanılmaktadır (Eryılmaz, 1998: 115; Emini ve Kocaoğlu, 2011). Bilgi teknolojileri yerel yönetimlerde kendini e-belediyecilik olarak göstermektedir. E-belediyecilik; internet sayfası açmak dışında bilgilendirici tüm süreçlerin, zaman ve mekan kısıtlaması olmadan, hızlı ve etkin bir biçimde elektronik ortamda gerçekleşebilmesi demektir (Henden ve Henden, 2005). E-devlet uygulamalarının kamu kurumu ile vatandaş arasındaki güveni artırdığını belirtmek mümkün olabilmektedir (Adolalı vd. 2012). 
Yerel yönetimler kendi oy verenleri ile onları yönetime katarak katılımcı bir yönetim anlayışı gerçekleştirir. E- belediyecilik halka öneri ve görüşlerini en hızlı şekilde yönetime bildirme şansı tanır. Ayrıca bu ilişkiler vatandaş, özel sektör gibi diğer organizasyonlarla olan iletişimin ve işbirliğinin güçlenmesine de yardımcı olur (Aydın, 2008). Bu açıdan yerel yönetimler halkla ilişkiler faaliyetlerini yoğun bir şekilde sürdürmektedir.

Yerel yönetimlerde halkla ilişkiler bazı ana işlevleri üstlenmiştir. Bu işlevleri şu şekilde belirtmek mümkündür (Bagnolet, 2008): Vatandaşlar ile yerel yönetim arasındaki görüş ve öneri alışverişini sağlamak, yerel yönetime tabi ve tabi olmayan vatandaşlarla iletişim sağlamak, yerel yöntemin belirlediğ $i$ amaçlar doğrultusunda halkı harekete geçirmektir.

Yerel yönetimlerin sunmuş olduğu E-belediyecilik uygulamaları vatandaşlara ve belediye çalışanlarına bir takım avantajlar sağlamaktadır. E-belediyecilik uygulamalarının vatandaşlara sağladığı yararların yanında da çalışanlarının iş yoğunluğunu da azaltmakta, çalışanın iş memnuniyetini artırmakta, işin tamamlanma süresinden kazanç sağlamaktadır (Demirtaş, 2012).

\section{İlgili çalışmalar}

İstanbul ilinde yer alan belediyelerin bilişim teknolojileri kullanımlarını inceleyen araştırmalar vardır. Üsküdar belediyesinin konu olduğu; belediyeye ait Twitter ve Facebook hesaplarının kullanılmasının halkla ilişkiler faaliyetlerine katkısı araştırılmıştır (Demirtaş, 2012). Ayrıca Değerli (2016), Kadıköy Belediyesini örneklem olarak ele almıştır. Bu çalışmada içerik analizi yöntem olarak seçilmiş ve belediyenin twitter sosyal ağ hesabını kamu yönetiminde kullanılmasının halkla ilişkiler faaliyetlerine ne kadar değer kattığı araştırılmıştır. Bilişim teknolojilerinin gelişimi sosyal medya kavramını meydana getirmiştir. Bu teknoloji insanların yaşamını etkilediği gibi birey-kurum arasındaki ilişkiyi de değiştirmiştir. E-belediyeciliğin sosyal medyayı da halkla ilişkiler faaliyetlerinde bir araç olarak kullandığı görülmüştür.

Akdeniz Bölgesi'nde yer alan yerel yönetimlerin önceleri e-belediyecilik anlayışının belediye teşkilat şeması, başkan ve belediye tarafından gerçekleştirilen faaliyetler hakkında bilgilerle sinırlı olduğu ancak e-belediyecilik uygulamalarında iletişim odaklı hizmetlere yoğunlaştığı bu hizmetlerin yanı sıra online hizmetlerin verildiği de tespit edilmiştir (Alodalı vb., 2012). 
Karbuz (2003), yerel yönetimlerde bilişim teknolojilerini teorik olarak incelemiştir. Alodalı vd. (2012) ise Akdeniz bölgesinde yer alan altı ilin yerel yönetimlerinin e-belediyecilik faaliyetlerini karşılaştırmalı olarak incelemişlerdir. Flak vd. (2005) belediyelerdeki e-devlet uygulamalarının belediyeler arası karşılaştırmaya imkan tanıdığını ifade etmektedirler. Hatta vatandaşların kendilerine sunulmasını arzu ettikleri hizmetleri farklı ülkelerdeki e-belediye hizmetlerini karşılaştırma açısından araştırmaların artırılmasını önermektedirler.

Sezer ve Vural (2010) araştırmalarında yerel yönetimlerin daha çok yerel halkı doğrudan etkileyen onların yaşamını daha kaliteli hale getiren hizmetleri sunmaya çalıştıklarını belirtmektedirler.

Başka bir araştırmanın sonuçlarına göre vatandaş ve kurum arasındaki iletişimin zamana ve mekana bağlı olmadan yürütülmesi, soruların hızlı cevaplandırılması, politikadan uzak bir şekilde halk dilinin kullanıldığı belirlenmiştir (Değerli, 2016).

Leenes (2004), araştırmasını yaptığı tarihte Hollanda'nın halkın beklentilerini karşılama yönünden e-devlet uygulamaları konusunda diğer Avrupa devletlerinden geri kalındığını belirtmektedir. Bu tarihlerde Türkiye, e-devlet uygulamaları olarak başkanı tanıtıcı bilgiler, belediye hiyerarşik yapısının internet ortamına aktarıldığı bilgilerle daha yeni tanışmaktaydı. Bilgi teknolojileri ile e-devlet uygulamaların kullanmada kullanıc deneyimi ve internet erişimi konularında lider konumda bulunan İskandinavya ülkeleri olduğu görülmektedir. Bu ülkeler e-devlet hizmetleri açısından olgunlaşmışlardır (Ronaghan, 2002; Dalziel 2004). Yıldırım ve Öner (2004) e-belediye uygulamalarını dünya ülkeleri bazında incelemiştir.

Yerel yönetimlerin modernleşmesi sürecinde e-devlet yalnızca hizmetlerin elektronik ortamdan verilmesi açısından değil vatandaş ile yönetim arasındaki ilişkilerin yeniden tanımlanması açısından yaratacağı katkılar dolayısıyla da gündemin önemli bir maddesi haline gelmiştir (Enticott, 2003). Yerel yönetimlerde bilişim teknolojilerinin uygulanması kurumlardaki iş süreçlerinin yeniden yapılandırılmasını sağlayarak hem kurum içi hem de kurum dışı ilişkiler için yarar sağlamıştır (Teng, 1994). Atik ve Taşçıŏlu (2009)'nun araştırması yerel yönetimlerde bilişim teknolojileri ile halkla ilişkiler uygulamalarının yürütüldüğü Erzurum Belediyelerini örneklem olarak seçmiştir.

Sayımer (2015) Türkiye'de yerel yönetimde bilişim teknolojilerinin kullanılmasının etkilerini şeffaflık, bilgi akışı, vatandaş katılımı açısından önemli 
sonuçları bulunduğu ve şu an ki şartların tartışılabilir olduğunu belirtmektedir.

Bilgi, iletişim teknolojilerinin takip edilebilmesi için gereken teknolojik eksikliklerin tamamlanması, mevcut teknolojiye uyumlanacak personelin temin edilerek eğitilmesi, kişisel bilgilerin korunmasının sağlanması gerekmektedir (Yüksel, 2005). Demir ve Filiz (2018)'in yapmış olduğu araştırmayı Sayıştay Başkanlığı çalışanları ile sınırlı tutmuştur. Bu araştırma kamu çalışanlarının bilgi teknolojileri kullanabilme yeterliliklerini incelemektedir. Ayrıca e-belediyecilik uygulamalarına halkın kolayca erişebilmesinin önerildiği araştırmaya göre sosyo-ekonomik düzeyi düşük vatandaşlar düşük gelire sahip olmakla birlikte e-devlet veya e-belediyecilik uygulamalarına erişim sağlayamamaktadırlar. Bu durum sunulan e-hizmetin tüm yerel halkın ulaşabilirliğinin sorgulanmasını gündeme getirmektedir (Servon, 2001: 419).

Kamu yönetiminde teknolojiden yararlanma bilincinin üst düzey yöneticilerde daha yüksek olduğu ifade edilmektedir. Ancak çoğu kurumda teknolojiden faydalanma düzeyinin emekleme aşamasında olduğunu ve kullanım düzeyinin düşük olduğu belirtilmektedir (Yüksel, 2005). Yerel yönetimlerde bilişim teknolojilerinin halkla ilişkiler uygulamalarında kullanılması yönünde sağladığı yararların yanı sıra kurumsal açıdan ya da halkın erişebilirliği açısından eleştirildiği görülmektedir.

Yönetim mekanizmaları ve paydaşları için bilgi stratejik olarak önem taşımaktadır. Bilginin toplanmasını, paylaşılmasını sağlayan teknolojiye bütün organizasyonlar adapte olmalıdır. Literatürdeki araştırmaların bilişim teknolojileri, teknolojiyi kullanabilme yeterliği, halkla ilişkiler gibi kavramları birbirinden ayrı olarak ele alındığı görülmüştür. Bu açıdan yerel yönetim çalışanlarının bilişim teknolojilerini kullanabilme açısından hangi aşamada olduğunu belirlemek araştırmanın amacını oluşturmaktadır.

\section{Yöntem}

\section{Çalışmanın amacı ve önemi}

E-devlet uygulamalarıyla 2000'li yılların başında tanışan Türkiye'de bilişim teknolojilerinin gelişiminin e-belediyecilik faaliyetlerine yansımaları incelenmek istenmiştir. Literatür taraması yapılarak, bilişim teknolojileri, e-beledi- 
yecilik konulu araştırmalar incelenmiştir. Yapılan araştırma sonuçları ve önerileri doğrultusunda; yerel yönetim çalışanlarının e-belediyecilik, halkla ilişkiler uygulamalarını nasıl algıladıklarının tespit edilmesi; bilişim teknolojileri kullanabilme yeterliliklerinin belirlenmesi çalışmanın amacını oluşturmaktadir.

\section{Evren ve örneklem}

Araştırma Kocaeli ilinde yer alan Başiskele, İzmit, Gölcük belediyesi çalışanlarına uygulanmıştır. Araştırmanın evrenini bu üç belediye çalışanları oluşturmaktadır. Gönüllü olarak anket formunu doldurmak isteyen çalışanları katılımcı olarak seçme imkanı tanıyan kolayda örneklem metodu tercih edilmiştir. Anket çalışmasına gönüllü olarak katılan 181 çalışan araştırmanın örneklemini oluşturmaktadır. Araştırma 2019 yılı haziran-ağustos aylarında gerçekleştirilmiştir. Üç ay süreyle veri toplanmıştır, araştırmanın bu sürede gerçekleştirilmesi zaman açısından bir kısıttır. Diğer bir kısıt ise üç ilçe belediyesi ile sınırlandırılmasıdır. İzinde olan, anket formunu cevaplamak istemeyen çalışanların olması da katılımcı sayısını kısıtlamaktadır.

\section{Veri toplama araci}

Anket formu dört bölümden oluşmaktadır. Formun ilk bölümünde Temel Teknoloji Yeterlikler (TTY) ölçeği için 12, ikinci bölümünde bilişim teknolojileri avantajı (BITA) ölçeği için 14 soru, üçüncü bölümde Halkla İlişkiler (Hİ) ölçeği için 21 soru bulunmaktadır. Son bölüm demografik bilgilere esas olan sorulara ayrılmıştır. Demografik sorular cinsiyet, yaş, gelir, medeni durum, eğitim düzeyi, pozisyon, kıdem olmak üzere yedi adettir.

Tekinarslan (2008)'nın tarafından kullanılan temel teknoloji yeterlikler (TTY) ölçeği 9 boyuttan oluşmaktadır. Temel teknoloji yeterlikler ölçeği araştırmanın amacına uygun olarak iki boyut ile anket formunda yer edinmiştir. Temel teknoloji yeterliklerinin alt boyutlarından biri olan TBKB (Temel Bilgisayar Kullanım Becerileri) ölçeğinin güvenirliği 0.91; Mİ (Medyalı İletişim) ölçeğinin güvenirliği $0.88^{\prime}$ dir. Emini ve Kocaoğlu (2011) tarafından kullanılan bilişim teknolojileri avantajı (BITTA) ölçeği çalışan avantajı (BİTÇA) ve kurum avantajı (BITTKA) olarak iki boyuta dağılmıştır. Bilişim teknolojileri çalışan 
avantajı ölçeğinin güvenirliği 0.71; bilişim teknlojileri kurum avantajı ölçeğinin güvenirliği 0.72 'dir. Şehirli (2018) tarafından kullanılan halkla ilişkiler ölçeği (HI)'nin güvenirliği 0.79 'dur.

Araştırmanın amacı doğrultusunda oluşturulan hipotezler aşağıdaki gibidir.

- H1: Temel teknoloji yeterliklerinin halkla ilişkiler üzerinde etkisi vardır.

- $\mathrm{H}_{2}$ : Bilişim teknolojileri avantajının halkla ilişkiler üzerinde etkisi vardır.

\section{Bulgular}

Araştırma verileri SPSS 21 programıyla analiz edilmiştir. Anlamlılık derecesi 0,05 olarak belirlenmiştir. Anket formunda yer alan ölçek maddelerine faktör analizi yapılmıştır. Açıklayıcı faktör analizinde Measures of Sampling Adequacy (MSA) değerleri incelenmiştir. Faktör yük değeri 0,50 ve üzeri olan değer yüksek kabul edilmektedir (Büyüköztürk, 2002). Açıklayıcı faktör analizinde Temel Teknoloji Yeterlikler (TTY) ölçeği temel bilgisayar kullanım becerileri (TBKB) ve medyalı iletişim (MI) olmak üzere iki boyuta dağılmıştır. Bilişim teknolojileri avantajı ölçeği (BITTA) ise çalışan avantajı (BİTÇA) ve kurum avantajı (BITKA) olmak üzere iki boyuta, halkla ilişkiler (HI) ölçeği iletişim teknolojileri (İTHI) ve online (OHI) olmak üzere iki boyuta dağılmıştır.

Temel bilgisayar kullanım becerileri ölçeği toplam 7 maddeden oluşmaktadır. Ancak faktör yükü 0,50 altında kalan maddeler çıkarıldıktan sonra 5 madde analiz kapsamına alınmıştır. Faktör analizi sonucunda temel bilgisayar kullanım becerileri ölçeğine ait iki madde analizden çıarılmıştır. Faktör yük değeri 0,50' un altında kalan 3 madde 0,341 ve 4 madde faktör yükü ,310 olduğu için analiz kapsamına alınmamıştır. Ölçeklere ait faktör değerleri tablo 1 'de verilmiştir. 
Tablo 1. Faktör analizi döndürülmüş bileşenler matrisi

\begin{tabular}{|c|c|c|c|c|c|c|}
\hline Madde & Faktör & Faktör & Faktör & Faktör & Faktör & Faktör \\
\hline TBKB1 & ,886 & & & & & \\
\hline TBKB2 & ,872 & & & & & \\
\hline TBKB3 & ,819 & & & & & \\
\hline TBKB4 & 813 & & & & & \\
\hline TBKB5 & 790 & & & & & \\
\hline Mi்1 & & ,960 & & & & \\
\hline мі2 & & ,954 & & & & \\
\hline мі3 & & 951 & & & & \\
\hline Mі4 & & ,825 & & & & \\
\hline Mi5 & & ,541 & & & & \\
\hline Bं̈С̧A1 & & & 911 & & & \\
\hline ВїТС̧A2 & & & 884 & & & \\
\hline ВїТÇA3 & & & 840 & & & \\
\hline BंТС̧A4 & & & 785 & & & \\
\hline BİTKA1 & & & & 825 & & \\
\hline BİTKA2 & & & & 820 & & \\
\hline ВİТКАЗ & & & & 819 & & \\
\hline ВїТКА4 & & & & 805 & & \\
\hline ВїТКА5 & & & & 793 & & \\
\hline ВİTKA6 & & & & 792 & & \\
\hline BİTKA7 & & & & 743 & & \\
\hline ВİTKA8 & & & & ,706 & & \\
\hline ВÏТКА9 & & & & 705 & & \\
\hline BİTKA10 & & & & ,666 & & \\
\hline їंसां1 & & & & & , 850 & \\
\hline їंНां2 & & & & & ,821 & \\
\hline їंНांз & & & & & 774 & \\
\hline їंНां4 & & & & & 773 & \\
\hline їंНां5 & & & & & 759 & \\
\hline і்тH்ட & & & & & 747 & \\
\hline їтні7 & & & & & 742 & \\
\hline їंНां8 & & & & & 710 & \\
\hline їंНां9 & & & & & 689 & \\
\hline İTHі10 & & & & & 660 & \\
\hline їंНां11 & & & & & 631 & \\
\hline İंHां12 & & & & & 607 & \\
\hline ОHі1 & & & & & & 848 \\
\hline OHां2 & & & & & & 837 \\
\hline ОHї3 & & & & & & 769 \\
\hline OHİ4 & & & & & & 751 \\
\hline OHां5 & & & & & & 723 \\
\hline ОHі்6 & & & & & & 710 \\
\hline OHİ7 & & & & & & 710 \\
\hline OHİ & & & & & & 706 \\
\hline OHіं9 & & & & & & 651 \\
\hline
\end{tabular}


Temel bilgisayar kullanım becerileri ölçeğinin faktör yükü 0,50'ten küçük olduğu için yenilenen faktör analizi sonucunda açıklanan varyans oranı 52,285'ten 70,017 ye yükselmiştir. Tablo 1'de yinelenen faktör analizi sonuçları verilmiştir.

Örneklemin yeterli hacme sahip olup olmadığının belirlenmesi amacıyla KMO değerine bakılmıştır. Bu değerin kabul edilebilir en alt değeri 0,50'dir. Bu değerlerden 0,50-0,60 arası kötü, 0,60-0,70 arası orta, 0,70-0,80 arası iyi, 0,80 ve yukarısı mükemmel bir örnek kitle hacmi olduğunu gösterir (Sipahi, 2010). KMO ve Barlett Testi sonuçları Tablo 2'de verilmiştir.

Tablo 2. KMO ve Barlett test değerleri

\begin{tabular}{|c|c|c|c|c|c|}
\hline \multirow{2}{*}{$\begin{array}{l}\text { TTY } \\
\mathrm{KMO}\end{array}$} & \multicolumn{2}{|c|}{ ВїА } & \multicolumn{3}{|c|}{ HI } \\
\hline & 805 & $\mathrm{KMO}$ & 890 & KMO & 957 \\
\hline$X^{2}$ & 613,678 & $\mathrm{X}^{2}$ & 2293,614 & $X^{2}$ & 3953,068 \\
\hline Barlett Test df & 21 & Barlett Test df & 91 & Barlett Test df & 210 \\
\hline Sig & , 000 & Sig & , 000 & Sig & , 000 \\
\hline \multirow[t]{2}{*}{ Öz değer } & 3,501 & Öz değer & 8,196 & Öz değer & 13,740 \\
\hline & 1,709 & & 1,778 & & 1,324 \\
\hline $\begin{array}{l}\text { Açıklanan } \\
\text { varyans }\end{array}$ & 70,017 & $\begin{array}{l}\text { Açılanan } \\
\text { varyans }\end{array}$ & 71,248 & $\begin{array}{l}\text { Açılanan } \\
\text { varyans }\end{array}$ & 71,732 \\
\hline
\end{tabular}

Temel teknoloji yeterlikler ölçeği iki boyuta dağılmıştır. Temel teknoloji yeterlikler ölçeğinin KMO değeri ,805, p değeri ,000'dır. Temel bilgisayar kullanım becerileri alt boyutunun öz değeri 3,501; medyalı iletişim alt boyutunun öz değeri 1,709'dur. Ölçeğin açıkladığı toplam varyans oranı 70,017'dir. Bilişim teknolojileri avantajı ölçeği iki boyuta dağılmıştır. Bilişim teknolojileri avantajı ölçeğinin KMO değeri ,890 ve p değeri ,000'dir. Ölçek boyutlarının öz değerleri 8,196; 1,778'dir. Ölçeğin açıkladı̆̆ı varyans oranı 71,248'dir. Halkla ilişkiler ölçeğinin KMO değeri ,957, p değeri 0,000'dir. Halkla ilişkiler ölçeği iki boyuta dağılmıştır. Boyutların öz değerleri sırasıyla 13,740 ve $1,324^{\prime}$ tür.

Tablo 3. Ölçeklerin Cronbach alfa katsayılan

\begin{tabular}{lll}
\hline Değişkenler & Güvenirlik Cronbach's Alpha & Madde Sayısı \\
\hline TBKB &, 889 & 5 \\
Mİ &, 809 & 5 \\
BiTÇA &, 919 & 4 \\
BiTKA &, 939 & 10 \\
ITHİ & 962 & 12 \\
OHİ & 950 & 9 \\
\hline
\end{tabular}


Ölçeklerin alt boyutlarına ait güvenirlik katsayıları Tablo 3'te verilmiştir. Ölçeğin güvenirlik katsayısı 0,60-0,80 arası ise güvenilir, 0,80' den büyük ise oldukça güvenilir olduğu kabul edilebilir (Yıldız ve Uzunsakal, 2018). Ölçeklerin güvenirlik katsayılarının oldukça yüksek olduğu görülmektedir.

Tablo 4. Değişkenlerin korelasyon analizi

\begin{tabular}{|c|c|c|c|c|c|c|c|c|}
\hline $\begin{array}{l}\text { Değiş- } \\
\text { kenler }\end{array}$ & TВKB & $M \dot{I}$ & ВїТС̧А & ВїТКА & ВїKA & ітHі & OHI & HI \\
\hline ТВКВ & 1 &, $54^{* *}$ &, $31^{* *}$ & $40^{* *}$ & ,38** &, $32^{* *}$ &, $32^{* *}$ &, $34^{* *}$ \\
\hline$M \dot{M}$ & & 1 &, $23^{* *}$ &, $21^{* *}$ &, $25^{* *}$ &, $30^{* *}$ & , $17^{* *}$ &, $34^{* *}$ \\
\hline BİKÇA & & & 1 &, $59^{* *}$ & , $96^{* *}$ &, $57^{* *}$ &, $50^{* *}$ &, $56^{* *}$ \\
\hline BİKKA & & & & 1 & ,78* &, $53^{* *}$ &, $54^{* *}$ &, $56^{* *}$ \\
\hline ВїКА & & & & & 1 &, $61^{* *}$ &, $57^{* *}$ & ,62** \\
\hline THI & & & & & & 1 &, $83^{* *}$ &, $97^{* *}$ \\
\hline $\mathrm{OHI}$ & & & & & & & 1 &, $94^{* *}$ \\
\hline$H \dot{I}$ & & & & & & & & 1 \\
\hline
\end{tabular}

Değişkenler arası ilişkilerin varlığını ortaya koyacak pearson katsayısı sonuçları Tablo 4'te verilmiştir. Sıfıra yakın bir kolerasyon katsayısı zayıf bir ilişkiyi, bire yakın bir kolerasyon katsayısı güçlü bir ilişkiyi göstermektedir (Tekin, 2014). Bu ifadeye göre; 0.26 - 0.49 zayıf, 0.50 - 0.69 orta, 0.70 - 0.89 yüksek, 0.90 - 1.00 çok yüksek ilişki olduğu şeklinde yorumlanabilmektedir (Köse, 2008).

Tablo 5.Temel bilgisayar kullanım becerilerinin online halkla ilişkilere etkisi

\begin{tabular}{lccccccc}
\hline & $\mathrm{R}$ & $\mathrm{R}^{2}$ & $\mathrm{~B}$ & $\beta$ & $\mathrm{T}$ & $\mathrm{F}$ & $\mathrm{P}$ \\
\hline Bağımsız değişken & & & & & & & \\
TBKB &, 328 &, 107 &, 666 &, 328 & 4,639 & 21,523 &, 00 \\
\hline
\end{tabular}

Bağımlı değişken OHI

Tabloda görüldüğü gibi temel bilgisayar kullanım becerilerinin online halkla ilişkiler üzerinde etkisini belirlemek için yapılan regresyon analizine göre değişkenlerin aralarında pozitif $(\beta=, 328)$ ve düşük $(R=, 328)$ düzeyde bir ilişki olduğu görülmektedir. Regresyon modelinde $p=0,00<0,05$ olduğundan temel bilgisayar kullanım becerilerinin online halkla ilişkiler üzerinde etkisi olduğu kabul edilmektedir. 
Tablo 6. Temel bilgisayar kullanım becerilerinin iletişim teknolojili halkla ilişkilere etkisi

\begin{tabular}{lccccccc}
\hline & $\mathrm{R}$ & $\mathrm{R}^{2}$ & $\mathrm{~B}$ & $\beta$ & $\mathrm{T}$ & $\mathrm{F}$ & $\mathrm{P}$ \\
\hline $\begin{array}{l}\text { Bağımsız değişken } \\
\text { TBKB }\end{array}$ &, 328 &, 107 &, 933 &, 326 & 4,621 & 21,354 &, 00 \\
\hline
\end{tabular}

Bağımlı değişken İTHI

Görüldügü üzere temel bilgisayar kullanım becerilerinin iletişim teknolojili halkla ilişkilere etkisini belirlemek için yapılan regresyon analizine göre değişkenlerin aralarında pozitif $(\beta=, 326)$ ve düşük $(R=, 328)$ düzeyde bir ilişki olduğu görülmektedir. Regresyon modelinde $\mathrm{p}=0,00<0,05$ olduğundan temel bilgisayar kullanım becerilerinin iletişim teknolojili halkla ilişkiler üzerinde etkisi olduğu kabul edilmektedir.

Tablo 7. Temel bilgisayar kullanım becerilerinin halkla ilişkilere etkisi

\begin{tabular}{lccccccc}
\hline & $\mathrm{R}$ & $\mathrm{R}$ & $\mathrm{B}$ & $\beta$ & $\mathrm{T}$ & $\mathrm{F}$ & $\mathrm{P}$ \\
\hline Bağımsız değişken & & & & & & & \\
TBKB &, 341 &, 116 & 1,600 &, 341 & 4,854 & 23,561 &, 00 \\
\hline
\end{tabular}

Bağımlı değişken Hİ

Görüldügü üzere temel bilgisayar kullanım becerilerinin halkla ilişkilere etkisini belirlemek için yapılan regresyon analizine göre değişkenlerin aralarında pozitif $(\beta=, 341)$ ve düşük ( $R=, 341)$ düzeyde bir ilişki olduğu görülmektedir. Regresyon modelinde $p=0,00<0,05$ olduğundan temel bilgisayar kullanım becerilerinin halkla ilişkiler üzerinde etkisi olduğu kabul edilmektedir.

Tablo 8. Medyalı iletişimin halkla ilişkilere etkisi

\begin{tabular}{|c|c|c|c|c|c|c|c|}
\hline 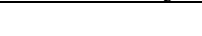 & $\mathrm{R}$ & $\mathrm{R}^{2}$ & B & $\beta$ & $\mathrm{T}$ & $\mathrm{F}$ & $\mathrm{P}$ \\
\hline $\begin{array}{l}\text { Bağ̆lmsiz değişken } \\
\text { Mİ }\end{array}$ & ,265 & ,070 & 638 & ,265 & 3,684 & 13,574 & ,00 \\
\hline
\end{tabular}

Bağımlı değişken Hİ

Medyalı iletişimin halkla ilişkiler üzerindeki etkisini belirlemek için yapılan regresyon analizine göre değişkenlerin aralarında pozitif $(\beta=, 265)$ ve düşük $(\mathrm{R}=, 265)$ düzeyde bir ilişki olduğu görülmektedir. Regresyon modelinde $\mathrm{p}=0,00<0,05$ olduğundan medyalı iletişimin halkla ilişkiler üzerinde etkisi olduğu kabul edilmektedir.

Tablo 9. Medyalı iletişimin iletişim teknolojili halkla ilişkilere etkisi

\begin{tabular}{lccccccc}
\hline & $\mathrm{R}$ & $\mathrm{R}^{2}$ & $\mathrm{~B}$ & $\beta$ & $\mathrm{T}$ & $\mathrm{F}$ & $\mathrm{P}$ \\
\hline $\begin{array}{l}\text { Bağımsız değişken } \\
\text { Mi் }\end{array}$ & & & & & & \\
\hline
\end{tabular}

Bağımlı değişken İTHI 
Medyalı iletişimin iletişim teknolojili halkla ilişkiler üzerindeki etkisini belirlemek için yapılan regresyon analizine göre değişkenlerin aralarında pozitif $(\beta=, 309)$ ve düşük $(R=, 309)$ düzeyde bir ilişki olduğu görülmektedir. Regresyon modelinde $p=0,00<0,05$ olduğundan medyalı iletişimin iletişim teknolojili halkla ilişkiler üzerinde etkisi olduğu kabul edilmektedir.

Tablo 10. Medyalı iletişimin online halkla ilişklere etkisi

\begin{tabular}{|c|c|c|c|c|c|c|c|}
\hline & $\mathrm{R}$ & $\mathrm{R}^{2}$ & B & $\beta$ & $\mathrm{T}$ & F & $\mathrm{P}$ \\
\hline Bağımsız değ işken & & & & & & & \\
\hline$M \dot{I}$ & 178 & 032 & 186 & 178 & 2,425 & 5,883 & ,016 \\
\hline
\end{tabular}

Bağımlı değişken OHI

Medyalı iletişimin online halkla ilişkiler üzerindeki etkisini belirlemek için yapılan regresyon analizine göre değişkenlerin aralarında pozitif $(\beta=, 178)$ ve düşük $(\mathrm{R}=, 178)$ düzeyde bir ilişki olduğu görülmektedir. Regresyon modelinde $\mathrm{p}=0,00<0,05$ olduğundan medyalı iletişimin online halkla ilişkiler üzerinde etkisi olduğu kabul edilmektedir.

Temel teknoloji yeterlikler ve alt boyutlarının halkla ilişkiler üzerinde etkisi olduğu bulunmuştur; $\mathrm{H}_{1}$ hipotezi kabul edilir.

Tablo 11. Bilişim teknolojileri çalışan avantajının halkla ilişkilere etkisi

\begin{tabular}{lccccccc}
\hline & $\mathrm{R}$ & $\mathrm{R}^{2}$ & $\mathrm{~B}$ & $\beta$ & $\mathrm{T}$ & $\mathrm{F}$ & $\mathrm{P}$ \\
\hline $\begin{array}{l}\text { Bağımsız değişken } \\
\text { BíKÇA }\end{array}$ &, 509 &, 259 &, 532 &, 509 & 7,904 & 62,479 &, 00 \\
\hline
\end{tabular}

Bağımlı değişken OHI

Bilişim teknolojileri çalışan avantajının online halkla ilişkiler üzerindeki etkisini belirlemek için yapılan regresyon analizine göre değişkenlerin aralarında pozitif $(\beta=, 509)$ ve orta $(R=, 509)$ düzeyde bir ilişki olduğu görülmektedir. Regresyon modelinde $p=0,00<0,05$ olduğundan bilişim teknolojileri çalışan avantajı online halkla ilişkilere üzerinde etkisi olduğu kabul edilmektedir.

Tablo 12. Bilişim teknolojileri çalışan avantajının iletişim teknolojili halkla ilişkilere etkisi

\begin{tabular}{|c|c|c|c|c|c|c|c|}
\hline & $\mathrm{R}$ & $\mathrm{R}^{2}$ & B & $\beta$ & $\mathrm{T}$ & $\mathrm{F}$ & $\mathrm{p}$ \\
\hline Bağımsız değişken & & & & & & & \\
\hline ВїKÇA & ,572 & ,327 & 841 &, 572 & 9,324 & 86,939 & ,00 \\
\hline
\end{tabular}


Bilişim teknolojileri çalışan avantajının iletişim teknolojili halkla ilişkiler üerindeki etkisini belirlemek için yapılan regresyon analizine göre değişkenlerin aralarında pozitif $(\beta=, 572)$ ve orta $(R=, 572)$ düzeyde bir ilişki olduğu görülmektedir. Regresyon modelinde $p=0,00<0,05$ olduğundan bilişim teknolojileri çalışan avantajının iletişim teknolojili halkla ilişkiler üzerinde etkisi olduğu kabul edilmektedir.

Tablo 13. Bilișim teknolojileri çalışan avantajının halkla ilișkilere etkisi

\begin{tabular}{lccccccc}
\hline & $\mathrm{R}$ & $\mathrm{R}^{2}$ & $\mathrm{~B}$ & $\beta$ & $\mathrm{T}$ & $\mathrm{F}$ & $\mathrm{p}$ \\
\hline $\begin{array}{l}\text { Bağımsız değişken } \\
\text { BíKÇA }\end{array}$ &, 569 &, 324 & 1,373 &, 569 & 9,259 & 85,725 &, 00 \\
\hline
\end{tabular}

Bağımlı değişken $H \dot{I}$

Bilişim teknolojileri çalışan avantajının halkla ilişkiler üzerindeki etkisini belirlemek için yapılan regresyon analizine göre değişkenlerin aralarında pozitif $(\beta=, 569)$ ve orta $(R=, 569)$ düzeyde bir ilişki olduğu görülmektedir. Regresyon modelinde $\mathrm{p}=0,00<0,05$ olduğundan bilişim teknolojileri çalışan avantajı halkla ilişkiler üzerinde etkisi olduğu kabul edilmektedir.

Tablo 14. Bilişim teknolojileri kurum avantajının online halkla ilişkilere etkisi

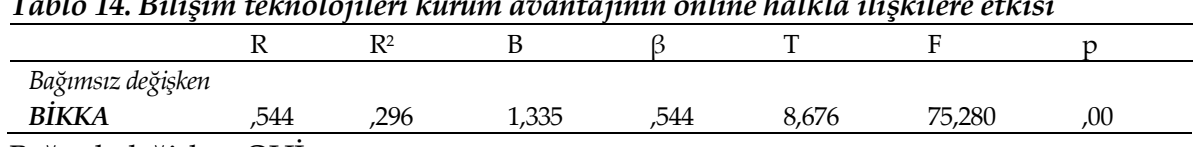

Bağımlı değişken OHI

Bilişim teknolojileri kurum avantajının online halkla ilişkiler üzerindeki etkisini belirlemek için yapılan regresyon analizine göre değişkenlerin aralarında pozitif $(\beta=, 544)$ ve orta $(R=, 544)$ düzeyde bir ilişki olduğu görülmektedir. Regresyon modelinde $\mathrm{p}=0,00<0,05$ olduğundan bilişim teknolojileri kurum avantajının online halkla ilişkiler üzerinde etkisi olduğu kabul edilmektedir.

Tablo 15. Bilişim teknolojileri kurum avantajının iletişim teknolojili halkla ilişkilere etkisi

\begin{tabular}{llllllll}
\hline & $\mathrm{R}$ & $\mathrm{R}^{2}$ & $\mathrm{~B}$ & $\beta$ & $\mathrm{T}$ & $\mathrm{F}$ & $\mathrm{p}$ \\
\hline $\begin{array}{l}\text { Bağımsız değışken } \\
\text { BíKKA }\end{array}$ &, 532 &, 283 & 1,833 &, 532 & 8,396 & 70,501 &, 00 \\
\hline
\end{tabular}

Bağımlı değişken İTHI 
Bilişim teknolojileri kurum avantajının iletişim teknolojili halkla ilişkiler üzerindeki etkisini belirlemek için yapılan regresyon analizine göre değişkenlerin aralarında pozitif $(\beta=, 532)$ ve orta $(R=, 532)$ düzeyde bir ilişki olduğu görülmektedir. Regresyon modelinde $\mathrm{p}=0,00<0,05$ olduğundan bilişim teknolojileri kurum avantajının iletişim teknolojili halkla ilişkiler üzerinde etkisi olduğu kabul edilmektedir.

Tablo 16. Bilişim teknolojileri kurum avantajının halkla ilişkilere etkisi

\begin{tabular}{lccccccc}
\hline & $\mathrm{R}$ & $\mathrm{R}^{2}$ & $\mathrm{~B}$ & $\beta$ & $\mathrm{T}$ & $\mathrm{F}$ & $\mathrm{p}$ \\
\hline $\begin{array}{l}\text { Bağımsız değişken } \\
\text { BíKKA }\end{array}$ &, 560 &, 314 & 3,169 &, 560 & 9,042 & 81,753 &, 00 \\
\hline
\end{tabular}

Bağımlı değişken Hİ

Bilişim teknolojileri kurum avantajının halkla ilişkiler üzerindeki etkisini belirlemek için yapılan regresyon analizine göre değişkenlerin aralarında pozitif $(\beta=, 560)$ ve orta $(R=, 560)$ düzeyde bir ilişki olduğu görülmektedir. Regresyon modelinde $p=0,00<0,05$ olduğundan bilişim teknolojileri kurum avantajının halkla ilişkiler üzerinde etkisi olduğu kabul edilmektedir.

Tablo 17. Bilişim teknolojileri kurum avantajının online halkla ilişkilere etkisi

\begin{tabular}{lccccccc}
\hline \multicolumn{2}{c}{$\mathrm{R}$} & $\mathrm{R}^{2}$ & $\mathrm{~B}$ & $\beta$ & $\mathrm{T}$ & $\mathrm{F}$ & $\mathrm{p}$ \\
\hline $\begin{array}{l}\text { Bağımsız değişken } \\
\text { BíKA }\end{array}$ &, 570 &, 325 &, 459 &, 571 & 9,276 & 86,035 &, 00 \\
\hline
\end{tabular}

Bağımlı değişken $\mathrm{OHI}$

Bilişim teknolojileri kurum avantajının online halkla ilişkiler üzerindeki etkisini belirlemek için yapılan regresyon analizine göre değişkenlerin aralarında pozitif $(\beta=, 570)$ ve orta $(R=, 570)$ düzeyde bir ilişki olduğu görülmektedir. Regresyon modelinde $\mathrm{p}=0,00<0,05$ olduğundan bilişim teknolojileri kurum avantajının online halkla ilişkiler üzerinde etkisi olduğu kabul edilmektedir.

Tablo 18. Bilişim teknolojileri kurum avantajinn iletişim teknolojili halkla ilişkilere etkisi

\begin{tabular}{lccccccc}
\hline & $\mathrm{R}$ & $\mathrm{R}^{2}$ & $\mathrm{~B}$ & $\beta$ & $\mathrm{T}$ & $\mathrm{F}$ & $\mathrm{p}$ \\
\hline $\begin{array}{l}\text { Bă̆ımsız değisken } \\
\text { BíKA }\end{array}$ &, 614 &, 377 &, 695 &, 614 & 10,413 & 108,423 &, 00 \\
\hline
\end{tabular}

Bağımlı değişken ITTHI 
Bilişim teknolojileri kurum avantajının online halkla ilişkiler üzerindeki etkisini belirlemek için yapılan regresyon analizine göre değişkenlerin aralarında pozitif $(\beta=, 614)$ ve orta $(R=, 614)$ düzeyde bir ilişki olduğu görülmektedir. Regresyon modelinde $\mathrm{p}=0,00<0,05$ olduğundan bilişim teknolojileri kurum avantajının iletişim teknolojili halkla ilişkiler üzerinde etkisi olduğu kabul edilmektedir.

Tablo 19. Bilişim teknolojileri kurum avantajının halkla ilişkilere etkisi

\begin{tabular}{lccccccc}
\hline & $\mathrm{R}$ & $\mathrm{R}^{2}$ & $\mathrm{~B}$ & $\beta$ & $\mathrm{T}$ & $\mathrm{F}$ & $\mathrm{p}$ \\
\hline $\begin{array}{l}\text { Bağımsız değişken } \\
\text { BíKA }\end{array}$ &, 621 &, 386 & 1,153 &, 621 & 10,611 & 112,600 &, 00 \\
\hline
\end{tabular}

Bağımlı değişken Hİ

Bilişim teknolojileri kurum avantajının halkla ilişkiler üzerindeki etkisini belirlemek için yapılan regresyon analizine göre değişkenlerin aralarında pozitif $(\beta=, 621)$ ve orta $(R=, 621)$ düzeyde bir ilişki olduğu görülmektedir. Regresyon modelinde $\mathrm{p}=0,00<0,05$ olduğundan bilişim teknolojileri kurum avantajının halkla ilişkilere üzerinde etkisi olduğu kabul edilmektedir. Bilişim teknolojileri avantajı ve alt boyutlarının halkla ilişkiler ve alt boyutları üzerinde etkisinin olduğu belirlenmiş, sonuç olarak $\mathrm{H}_{2}$ hipotezi de kabul edilmiştir.

Anket formunda çalışanların cinsiyet, yaş, gelir, medeni durum, eğitim düzeyi, pozisyon, kıdem olmak üzere yedi adet demografik soru bulunmaktadır. Demografik değişkenlerin temel teknoloji yeterlikler, bilişim teknolojileri avantajının halkla ilişkiler ve alt boyutları üzerinde farklılık yaratıp yaratmadığına ilişkin analizler yapılmıştır. Cinsiyet, medeni durum için t-testi, diğer demografik değişkenler için anova analizi yapılmıştır. Cinsiyet, gelir, medeni durum, pozisyon, kıdem ile bağımlı değişkenler arasında bir ilişki bulunamamıştır ( $p>0,05)$. Demografik değişkenlerden yaşın ve eğitim düzeyinin bağımlı değişken üzerinde farklılık yarattı̆̆ı belirlenmiştir. Yaşın medyalı iletişimin üzerinde bir farklılık yarattı̆̆ görülmüştür. Gruplar arası ortalamanın karesi 117,077; grup içi ortalamaların karesi 44,516, $\mathrm{F}=2,630$, $\mathrm{p}=0.02$ 'dir. Yaş gruplarından 27-33 yaş ile 48-54 yaş arasında farklılık görülmüştür. 27-33 yaş arasındaki çalışanların 48-54 yaş arasındaki çalışanlardan daha yüksek medyalı iletişimin düzeyine (ortalama fark 6,$14 ; \mathrm{p}=0,037$ ) sahip olduğu görülmüştür. Çalışanların yaşı arttıkça medyalı iletişim düzeyleri azalmaktadır yorumu yapılabilmektedir. 
Eğitim düzeyinin halkla ilişkiler üzerinde bir farklılık yarattı̆g görülmüştür. Gruplar arası ortalamanın karesi 2119,710; grup içi ortalamaların karesi 39362,48; F=2,836; $p=0.04$ 'tür. Lisans ve önlisans eğitim düzeyine sahip çal1şanlar arasında farklılık görülmüştür. Lisans eğitim seviyesine sahip çalışanların halkla ilişkiler düzeyleri önlisans eğitim seviyesine sahip çalışanlardan daha düşük bulunmuştur (ortalama fark $-8,13 ; \mathrm{p}=0,012$ ).

\section{Tartışma}

Çalışanların temel teknoloji yeterlikler ve alt boyut düzeyleri ile halkla ilişkiler ve alt boyut düzeyleri bilişim teknolojileri avantajı, halkla ilişkiler arasında doğru yönlü bir ilişki olduğu görülmektedir. Benzer bir sonuca ulaşan Demirtaş (2012) halkla ilişkilerde Üsküdar Belediyesinin bilişim teknolojilerinden etkin bir şekilde faydalandığını belirlemiştir. Belediye bilişim teknolojileri vasıtasıyla vatandaşlarla iletişimi sürdürüp onları memnun etmektedir.

Araştırma sonuçlarında belediye çalışanlarının cinsiyeti ile temel teknoloji yeterlikler, bilişim teknolojileri avantajı, halkla ilişkiler ve alt boyutları arasında bir ilişki bulunamamıştır. Bu bulguların tersine Demir ve Filiz (2018), Kandil İngeç (2014) kamu çalışanlarının teknoloji kullanım seviyelerini cinsiyet temelinde inceleyerek kadın katılımcıların bilişim teknolojileri kullanma seviyelerinin erkeklerden daha yüksek olduğu belirlemişlerdir.

Çalışanların pozisyonlarının temel teknoloji yeterlikler, bilişim teknolojileri avantajı, halkla ilişkiler ve alt boyutları üzerinde farklılık yaratmadığı görülmüştür. Demir ve Filiz (2018) kamu çalışanlarının unvanlarına bağlı olarak bilişim teknolojileri kullanma seviyelerinin farklılık göstermediğini belirtmişlerdir. Ayrıca belediye çalışanlarının kıdemleri ile temel teknoloji yeterlikler, bilişim teknolojileri avantajı, halkla ilişkiler ve alt boyutları arasında bir farklılık bulunamamıştır. Demir ve Filiz (2018) kıdem ile bilişim teknolojileri kullanım düzeyleri arasında ters bir ilişki bulmuşlardır.

Çalışanların eğitim seviyelerinin tespiti için mezuniyet durumlarına yönelik soru sorulmuştur. Ancak mezun olunan bölüm hakkında bilgi alınmamıştır. Lisans eğitim seviyesine sahip çalışanların halkla ilişkiler düzeylerinin önlisans mezunu çalışanlardan daha düşük olmasının nedeni önlisans mezunu çalışanlarının halkla ilişkiler mezunu olabilecekleri yönündedir.

Çalışanların temel teknoloji yeterlikler düzeyleri arttıkça bilişim teknolojileri avantajı, halkla ilişkiler düzeylerinin arttığını belirtmek mümkündür. 
Bu açıdan bilişim teknolojilerini etkin bir şekilde kullanabilen çalışanlara sahip olunması önem taşımaktadır. Bu bağlamda yerel yönetimlerin insan kaynakları departmanına önemli görevler düşmektedir. Ayrıca bilişim teknolojileri konusunda çalışanların eğitim açığına sahip olmaları durumunda vatandaşa yerinde hizmet sunamayacak ve vatandaş memnuniyeti azalacaktır. Çalışanlar açısından eğitim eksikliğinin giderilmesini sağlamak insan kaynakları biriminin görevidir. Ĕ̆itim verilmesine rağmen teknoloji kullanımı konusunda eksikliğini kapatamayan çalışanlar emekliliğe yönlendirilebilir ya da vatandaşla yüz yüze iletişim kurabileceği bir departmanda görevlendirilebilir.

Bu çalışma sanayi kenti olan Kocaeli ve Kocaeli'ye bağlı Başiskele, İzmit, Gölcük belediyelerinde gerçekleştirilmiştir. Gelişmiş şehirlerin e-belediyecilikle vatandaşların yararına hizmetler sunduğunu, halkla ilişkiler faaliyetlerinin bilişim teknolojileri kullanılarak sürdürdüğünü belirtmek yerinde olacaktır. Günümüzde telefonlardan da erişilebilen e-belediyecilik uygulamalarının teknolojiyi takip eden her vatandaşa ulaşabildiğini söylemek yerinde olacaktır.

Gelecekteki çalışmalar için çalışanların mezun oldukları bölüm bilgiler hakkında soru sorulması önerilmektedir. Literatürde e-belediyecilik çalışmalarının vatandaş ve çalışan algısını ayrı ayrı ölçtüğü görülmektedir. Tek bir çalışmada her iki tarafın bilişim teknolojileri, halkla ilişkiler uygulamaları algıları ölçülebilir. Ayrıca doğu ve batı illeri arası e-belediyecilik uygulamalarının karşılaştırılması Türkiye'deki e-belediyeciliğin konumu hakkında fikir verebilecektir. 


\title{
EXTENDED ABSTRACT
}

\section{Information Technologies Usage, Competence and Public Relations in Local Administrations: The Case of Kocaeli}

\author{
Burcu Üzüm - Leyla Şenol \\ Kocaeli University
}

With the development of technology, information technologies such as estate, e-municipality have taken its place in public administration as an element of accountability, transparency, and as an element providing access to information in the fastest way. The common ground of information technologies and communication technologies is called information technologies (Karbuz, 2003). Within information technologies, while e-state applications is a service used by all citizens of a country, e-municipality is used by the citizens in a city or district. With this study, it has been aimed at giving information about local governments and information technologies and public relations which is one of the related concepts in local governments. In addition, it has been tried to confirmed how these concepts are perceived by local officials and employees. Besides, it has been analysed whether the demographic changes of the employees make any difference in the use and competence of information technologies, and public relations.

E-municipality applications provide several advantages for the citizens and local officials. Apart from the advantages for the citizens, e-municipality applications reduce the workload of employees, increases job satisfaction, and saves time from the job's completion period (Demirtaş, 2012).

By making a literature review, the studies about information technologies and e-municipality have been analysed. The aim of this study is to identify how local officials and employees perceive e-municipality and public relations and to determine their capabilities to use information technologies in accordance with the results and recommendations of the studies. 
The data of the study has been gathered from the employees of Başiskele, İzmit, Gölcük municipality in Kocaeli. The population is formed of the officials of these three municipalities. The convenience sampling method which gives opportunity to the officials wanting to fill the survey as a volunteer to have the possibility to choose as a participant has been used. 181 officials who have taken part in the survey voluntarily constitute the sample of the study. The research was conducted from June to August, 2019 and data was collected for three months.

The hypothesis generated in line with the aim of the study are as follows;

- H1: Efficiency of basic technologies have an impact on public relations.

- $\mathrm{H}_{2}$ : The advantage of information Technologies has an impact on public relations.

It has been indicated that there is a positive relationship between basic technologies competence and its sub-dimensions and public relations and its sub-dimensions. In addition, it has been concluded that there is a positive relationship between information technologies advantage and its subdimensions and public relations and its sub-dimensions. It has been revealed that gender, income, marital status, position and seniority do not make any difference in basic technology competence, information technologies advantage and public relations. However, it has been detected that from the demographic changes age and education level make a difference in basic technology competence, information technologies advantage and public relations. As the level of basic technology competence of the officials increases, the level of information technologies advantage and public relations also increases. In order for local governments provide citizens with fast, transparent and efficient service, officials must use information technologies effectively. In this respect, it is suggested that educational needs of local officials and employees must be considered.

Based on the results of the study, it has been found out that there is no relationship between the gender of local officials and basic technology competence, information technologies advantage and public relations and sub-dimensions. Unlike these findings, Demir and Filiz (2018), Kandil İngeç (2014) have pointed out that the level of use of information technologies of women is higher than men's by analysing public officials' level of use of technology in terms of gender. 
It has been observed that the position of officials do not make any difference in basic technology competence, information technologies advantage and public relations and sub-dimensions. Demir and Filiz (2018) have asserted that the level of use of information technologies do not change in line with the title of public officials. Moreover, it has been found out that there is no inverse relationship between the seniority of the officials and basic technology competence, information technologies advantage and public relations and sub-dimensions. However, Demir and Filiz (2018) have ascertained that there is an inverse relationship between seniority and the level of use of information technologies.

In order to identify the education level of the officials, a question about graduation level was asked. Nevertheless, participants were not asked about the departments which they graduated from. The reason why public relations level of officials having undergraduate degree is lower than the ones having associate degree is that officials with associate degree may be graduates of public relations.

It can be claimed that as the officials' level of basic technology competence increases, the level of public relations increases. In this respect, it is important to have employees who can use information technologies effectively. In this regard, public relations departments of local governments play an important role. Employees' lack of education must be fulfilled by human resources. Employees who cannot improve themselves in terms of the use of technology even though they have been trained could be directed to retirement or they could be employed in a department where they communicate with the citizens face to face.

It is important to point out that in developed cities, thanks to e-municipality, services which are for the good and satisfaction of the citizens are provided, public relations services are maintained by using information technologies. It is possible to claim that nowadays, e-municipality applications which can be attained via mobile phones as well reach every citizen who follow technology.

It is suggested for the future studies that a question related to the department where the participants graduated from must be asked. In literature, it has been realized that in the studies based on e-municipality, the perception of citizens and employees has been measured separately. How- 
ever, perception of the applications of information technologies and public relations in terms of citizens and employees can be measured in the same study. In today's world which is becoming digitalized fast globally in every field, if the number of studies increases, it will contribute greatly.

\section{Kaynakça / References}

Aktel, M. (2003). Küreselleşme ve Türk kamu yönetimi. Ankara: Asil Yayın Dağıtım.

Alodall, B. F., Tuncer, A., Usta, Sefa ve Halis, M. (2012). Yerel yönetimlerde e-belediyecilik uygulamaları: Akdeniz Bölgesi örneği. Manas Sosyal Araşttrmalar Dergisi, 1(1), 83-95.

Anttiroiko, A.V. (2001). Toward the European information society. Communications of the ACM, 44(1), 31-35.

Atik, A. ve Taşçığlu, R. (2009). Radyo ve televizyonun yerel yönetimlerin halkla ilişkiler uygulamalarında iletişim yöntem ve aracı olarak kullanımı: Erzurum belediyeleri örneği. ZKÜ Sosyal Bilimler Dergisi, 5(10), 159-170.

Aydın, M. (2008). Sosyal politika ve yerel yönetimler. İstanbul: Yedirenk Yayınları.

Bagnolet, V. D. (2008). Communication et relations publiques. 10.2.2020 tarihinde http://www.villebagnolet.fr/index.php?pge=317 adresinden erişilmiştir.

Büyüköztürk, Ş. (2002). Faktör analizi: temel kavramlar ve ölçek geliştirmede kullanım. Kuram ve Uygulamada Ĕ̆itim Yönetimi. 32 470-483.

Castells, M. (2000). Globalization \& Identity in the network society: A rejoinder to calhoun, lyon and touraine. Prometheus, 4, 107-123.

Coşkun, B. ve Turgay, U. (1999). Türkiye'de yerel yönetimlerin gelişimi. Muğla: Muğla Üniversitesi Yayınları.

Dalziel, D. (2004),. Government online: A multi-country study of e-government usage, the world association of research professionals, ESOMAR Report.

Değerli, A. (2016). A $\breve{g}$ toplumunun iletişimi ekseninde yerel yönetimlerin sosyal medya kullanım düzeyi: Kadıköy Belediyesi örneği. Marmara Üniversitesi Öneri Dergisi, 12(46), 63-79.

Demir, N. ve Filiz, S. B. (2018). Kamu çalş̧anlarının bilgi ve iletişim teknolojilerini kullanım düzeylerinin incelenmesi: Sayıştay Başkanlığı örneği. Sayıştay Dergisi, 108, 149-174.

Demirtaş, M. (2012). Yerel yönetimlerde bir halkla ilişkiler çalışması olarak sosyal paylaşım ağlarının kullanımı: Üsküdar Belediyesi örneği. E-Journal of New World Sciences Academy, 7(4), 291-314.

Enticott, G. (2003). Researching Local Government Using Electronic Survey., Local Government Studies, 29(2), 52-67. 
Emini, F. T. ve Kocaoğlu, M. (2011), Bilişim teknolojileri kullanımının hizmet sunumuna etkileri: Konya İ Özel İdaresi örneği. Süleyman Demirel Üniversitesi İktisadi ve İdari Bilimler Fakültesi Dergisi, 16(2), 179-200.

Eryılmaz, B. (1998). Kamu yönetimi. İstanbul: Erkam Matbaacılık.

Flak, L. S., Olsen, D.H. and Wolcott, P. (2005). Local E-Government in Norway current status and emerging issues. Scandinavian Journal of Information Systems, $17(2), 41-84$.

Henden, H. B. ve Henden, R. (2005). Yerel yönetimlerin hizmet sunumlarındaki değişim ve e-belediyecilik. Elektronik Sosyal Bilimler Dergisi, 4(14), 48-66.

Kandil İngeç, Ş., Ağa, S. ve Şahingöz, M. (2014). Kız teknik ve meslek lisesi öğrencilerinin bilgi ve iletişim teknolojileri becerilerinin farklı değişkenler açısından incelenmesi. Ĕ̆itim ve Öğretim Araştırmalan Dergisi, 3(3), 350-364.

Karbuz, H. (2003). Yerel yönetimler ve bilgi teknolojileri. Ankara Üniversitesi Sosyal Bilimler Enstitüsü Basılmamış Yüksek Lisans Tezi, Ankara.

Köse, K. (2008), Korelasyon ve regresyon analizi. http://file.toraks.org.tr/TORAKSFD23NJKL4N/4H3BG3]H/mse-ppt-pdf/Kenan KOSE3.pdf. Adresinden erişilmiştri.

Leenes, R. (2004). Local e-government in the Netherlands: From ambitious policy goals to harsh reality. Austrian Academy of Scrences Vienna, 4(4), 1-23.

Nadaroğlu, H. (2001). Mahalli idareler. İstanbul: Beta Basım.

Parlak, B. ve Sobacı, Z. (2008), Kuram ve uygulamalarda kamu yönetimi ulusal ve global perspektifler. İstanbul: Alfa Aktüel.

Rahman, H. (2010). Handbook of research on e-government readiness for information and service exchange: Utilizing progressive information communication technologies. Information Science References: New York.

Ronaghan, S. A. (2002). Benchmarking e-government: A global perspective - assessing the progress of UN member states. United nations division for public economics and public administration report, New York.

Sayımer, İ. (2015). Electronic government in public administration: an assessment of local government web sites in Turkey. International Journal of Ebusiness And Egovernment Studies, 7(2), 1-16.

Servon, L.J. ve Nelson, M. (2001). Community Technology centers and the urban technology gap. International Journal of Urban and Regional Research, 25(2), 419-426.

Sezer, Ö. ve Vural, T. (2010). Kamu hizmetlerinin sunumunda devletin değişen rolü ve merkezi yönetim ile yerel yönetimler arasında yetki ve görev paylaşımı. Maliye Dergisi, 159, 203-219. 
Şehirli, F. (2018). Kobilerde halkla ilişkiler: Online halkla ilişkiler faaliyetlerinin iletişim performansı açısından rolü. Basılmamış Doktora Tezi, Selçuk Üniversitesi Sosyal Bilimler Enstitüsü, Konya

Sipahi, Ç. (2010). Sosyal Bilimlerde SPSS ile Veri Analizi. İstanbul: Beta Yayınevi.

Tekinarslan, E. (2008). A valıdity and reliability study of the basic technology competencies scale for educators. Electronic Journal of Social Sciences, 7(26), 186-205.

Tekin, V. N. (2014). SPPS uygulamal istatistik teknikleri. Ankara: Seçkin Kitapevi.

Teng, J.T.C., Grover, V. ve Fiedler, K. (1994). Re-designing Business Processes Using Information Technology. Long Range Planning, 27(1), 95-106.

Ulusoy, A. ve Akdemir, T. (2002). Yerel yönetimler. Ankara: Seçkin Yayıncllk.

Yıldırım, U. ve Öner, Ş. (2004). Bilgi toplumu sürecinde yerel yönetimlerde eğitimbilişim teknolojisinden yararlanma: Türkiye'de e-belediye uygulamaları. The Turkish Online Journal of Educational Technology, 3(1), 49-60.

Yıldız, D. ve Uzunsakal, E. (2018). Alan araştırmalarında güvenilirlik testlerinin karşılaştırlması ve tarımsal veriler üzerine bir uygulama. Uygulamah Sosyal Bilimler Dergisi, 1, 14-28.

Yüksel, F. (2005). Bilgi teknolojileri ve yerel yönetimler. SÜ IÏBF Sosyal ve Ekonomik Araştırmalar Dergisi 10, 247-259.

\section{Kaynakça Bilgisi / Citation Information}

Üzüm, B. ve Şenol, L. (2020). Yerel yönetimlerde bilişim teknolojileri kullanımı, yeterliği ve halkla ilişkiler: Kocaeli örneği. OPUS-Uluslararası Toplum Araştırmaları Dergisi, 16(Özel Sayı), 3411-3435. DOI: 10.26466/opus.734149 